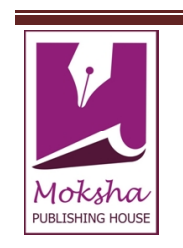

INTERNATIONAL RESEARCH JOURNAL OF PHARMACY

www.irjponline.com

ISSN $2230-8407$

Research Article

\title{
SPECTROPHOTOMETRIC METHOD FOR SIMULTANEOUS ESTIMATION OF FORMOTEROL FUMARATE AND MOMETASONE FUROATE IN RESPICAPS
}

\author{
Bhangale Pallavi Raghunath, Jain Hemant Kumar* \\ Sinhgad College of Pharmacy, Vadgaon (BK.), Pune, Maharashtra, India \\ *Corresponding Author Email: hemantkjain2001@yahoo.co.in
}

Article Received on: 16/03/13 Revised on: 03/04/13 Approved for publication: 01/05/13

DOI: $10.7897 / 2230-8407.04650$

IRJP is an official publication of Moksha Publishing House. Website: www.mokshaph.com

(C) All rights reserved.

\section{ABSTRACT}

The present work represents a UV-Spectrophotometric method for the simultaneous estimation of Formoterol Fumarate (FF) and Mometasone Furoate (MF) in respicaps dosage form. This method is based on area under curve (AUC) in the wavelength range of 210-220nm and 242-252nm. Linearity was found in the concentration ranges of $3-18 \mu \mathrm{g} / \mathrm{ml}$ and $6-21 \mu \mathrm{g} / \mathrm{ml}$, for Formoterol Fumarate and Mometasone Furoate, respectively. This method was validated as per International Conference on Harmonization (ICH) guidelines. Validation results suggest that the proposed method is simple, rapid, accurate, sensitive and precise that can be applied for routine estimation of FF and MF in bulk drug and combined dosage form.

Keywords: Simultaneous estimation, Formoterol Fumarate, Mometasone Furoate, Area under curve, Ultraviolet spectrophotometry, Respicaps.

\section{INTRODUCTION}

Formoterol Fumarate dihydrate (FF) is chemically known as N-[2-hydroxy-5-[(1RS)-1-hydroxy-2-[[(1RS)-2-(4-methoxyphenyl)-1-methylethyl] amino] ethyl] phenyl] formamide (E)butanedioate dihydrate $^{1}$ (Figure 1). It is a selective beta-2 $\left(\beta_{2}\right)$ adrenergic receptor agonist which acts as bronchodilator for the treatment of asthma by relaxing muscle spasms in the air passages of lungs ${ }^{2-4}$. This drug is official in $\mathrm{USP}^{5}, \mathrm{EP}^{6}, \mathrm{IP}^{7}$ and $\mathrm{BP}^{8}$. Mometasone Furoate (MF) is chemically known as 9, 21-dichloro-11ß-hydroxy-16 $\alpha$-methyl-3, 20-dioxopregna1, 4-diene-17-yl furan-2-carboxylate ${ }^{9}$ (Figure 2). It is a corticosteroid which helps to decrease inflammation in the lungs and controls various asthmatic symptoms ${ }^{6,10}$. This drug is official in $\mathrm{BP}^{8}$, $\mathrm{USP}^{9}$ and $\mathrm{EP}^{11}$. The combination of $\mathrm{FF}$ and MF is used to control asthma effectively, which cannot be control by single drug alone ${ }^{4,6}$. Literature survey reveals that several analytical methods have been published for the estimation of Formoterol Fumarate alone or in combination with other drugs. Some of these methods include HPLC ${ }^{12-15}$, $\mathrm{GC}^{16}$ and UV spectrophotometry ${ }^{17}$. Various methods have been reported for estimation of Mometasone Furoate alone or in combination with other drugs including UV spectrophotometry $^{18}$ and supercritical fluid chromatography ${ }^{19}$. However, no UV method has been reported for simultaneous estimation of FF and MF by area calculation technique. Therefore, attempts were made to develop a UV spectrophotometric method by area under curve (AUC) for simultaneous estimation of Formoterol Fumarate Dihydrate and Mometasone Furoate in respicaps.

\section{MATERIALS AND METHODS Instruments}

A Shimadzu UV 1800 double beam spectrophotometer with spectral band width of $1 \mathrm{~nm}$ and a pair of matched quartz cell and UV probe software, was used for this study. Shimadzu AX200 (Japan) digital balance and Spectrolab UCB40 (Germany) ultrasonicator were also used in the work.

\section{Reagents and Materials}

The active pharmaceutical ingredients of Formoterol Fumarate Dihydrate and Mometasone Furoate were supplied as gift sample by Zydus Cadilla Pvt. Ltd., Ahmedabad, India. Respicaps (Formost 200 contains $6 \mu \mathrm{g}$ of Formoterol Fumarate and $200 \mu \mathrm{g}$ of Mometasone Furoate) were procured from the market, AR grade methanol was obtained from Merck specialties Pvt. Ltd., Mumbai, India and Acrodisc PSF GHP $0.45 \mu \mathrm{m}$ nylon filters were purchased from Pall Life Science limited, Mumbai, India.

\section{Preparation of Standard Solutions}

Formoterol Fumarate $(100 \mathrm{mg})$ was accurately weighed and transferred to a $100 \mathrm{ml}$ volumetric flask containing small amount of methanol. The drug was dissolved with sonication and the final volume was adjusted with methanol up to the mark. This standard stock solution was further diluted with same solvent to get $12 \mu \mathrm{g} / \mathrm{ml}$. Similarly, solution of Mometasone Furoate in methanol was also prepared to get a concentration of $12 \mu \mathrm{g} / \mathrm{ml}$.

\section{Preparation of sample solution}

Twenty capsules were accurately weighed and average weight was calculated. Capsule shells were removed; powder equivalent to one capsule was weighed accurately and transferred into a $10 \mathrm{ml}$ volumetric flask. Then, Methanol $(5 \mathrm{ml})$ was added to dissolve the content present in this flask and $0.94 \mathrm{ml}$ of standard stock solution of Formoterol Fumarate was added. This solution was sonicated for 30minutes with occasional swirling and diluted up to mark with same diluent. This solution was filtered using Acrodisc PSF GHP $0.45 \mu \mathrm{m}$ nylon filters and further subjected for UV analysis.

\section{Area under curve method}

The AUC method ${ }^{20,21}$ involves area calculation of integrated value of absorbance with respect to wavelength in indicated region of wavelengths. Area calculation processing item calculates the area bounded by the curve and horizontal axis $^{22}$. Here horizontal axis represents baseline.

$$
\text { area calculation }(\alpha+\beta)-\int_{\lambda 2}^{\lambda 1} A d \lambda
$$


Whereas, $\alpha$ is area of portion bounded by curve data and a straight line connecting the start and end point, $\beta$ is area of portion bounded by a straight line connecting the start and end point on curve data and horizontal axis, $\lambda_{1}$ and $\lambda_{2}$ are wavelengths representing start and end point of curve region. The selection of wavelength range was done on the basis of linearity between area under curve and concentration. Working standards were prepared by dilutions of standard stock solutions of these drugs and these solutions were scanned in the spectrum mode $(200-400 \mathrm{~nm})$, an overlain spectrum was recorded (Figure 3 ). The selected sampling wavelength ranges for calculation of area under curve were 220-230 nm and 242.0-252.0 nm. Similarly, Area under curve of sample solutions was also measured at these selected wavelength ranges.

\section{Method Validation}

Validation of an analytical procedure is the process by which it is established by laboratory studies that the performance characteristics of the procedure meet the requirements for the intended analytical application ${ }^{23}$. The proposed method was validated for various parameters such as linearity, precision, accuracy, Limit of detection (LOD), Limit of Quantitation (LOQ) according to ICH Q2 (R1) guidelines.

\section{Linearity and Range}

The linearity of response for Formoterol Fumarate and Mometasone Furoate was determined by measuring the area under curve in the concentration range of $3-18 \mu \mathrm{g} / \mathrm{ml}$ of Formoterol Fumarate and $6-21 \mu \mathrm{g} / \mathrm{ml}$ of Mometasone Furoate. The calibration curves were plotted between concentration range and area under curve, as shown in Figure 4 and 5 for $\mathrm{FF}$ and MF, respectively.

\section{Precision}

Precision of the method was studied by intra and inter-day variations in the test method of FF and MF. Method repeatability (intra-day precision) was evaluated by assaying six samples, prepared as described under sample preparation. Inter day precision was performed by assaying six samples in different days as described in the sample preparation. The results were expressed as percentage relative standard deviation (\%RSD) in Table 2 and 3.

\section{Accuracy}

Accuracy of the method was determined by calculating recovery of $\mathrm{FF}$ and $\mathrm{MF}$ at $80 \%, 100 \%$ and $120 \%$ level of sample solutions of FF and MF. The accuracy of the analytical method was established in triplicate across its range. The results of recovery experiments are given in Table 4.

\section{Limit of Quantitation (LOQ) and Limit of Detection (LOD)}

Six sets of known concentrations were prepared for both drugs. Calibration curves were plotted for each set. LOD and LOQ were calculated using the formulae as

$$
\begin{aligned}
& L O D=3.3 \frac{S D}{S} \\
& L O Q=10 \frac{S D}{S}
\end{aligned}
$$

Where, $\mathrm{S}$ is value of slopes of calibration plot and SD is calculated using values of $y$ intercepts of regression equations. The results of LOD and LOQ are presented in Table 5.

Table 1: Results of Analysis of Respicaps Formulation

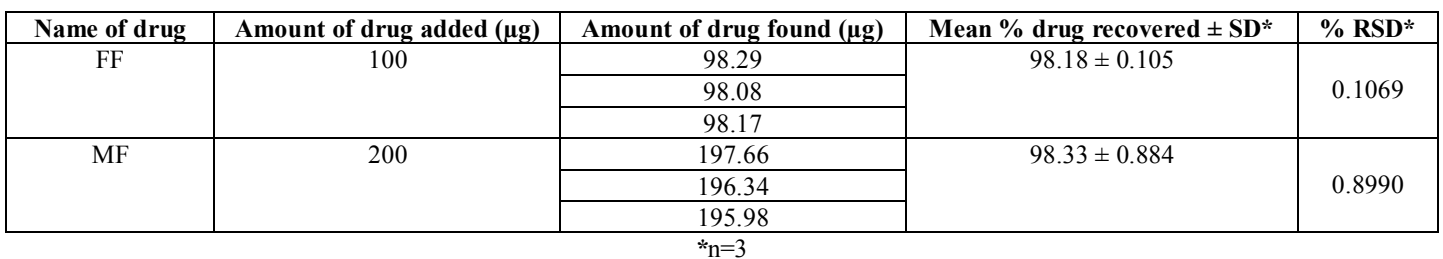

Table 2: Results of Intraday Precision

\begin{tabular}{|c|c|c|c|}
\hline Drug & Concentration Added $(\boldsymbol{\mu g} / \mathbf{m l})$ & Mean \% assay \pm SD & \% RSD* \\
\hline FF & 10 & $97.84 \pm 1.08$ & 1.36 \\
\hline MF & 20 & $98.37 \pm 1.24$ & 1.27 \\
\hline \multicolumn{4}{|r}{$*_{n}=6$}
\end{tabular}

Table 3: Results of Inter-Day Precision

\begin{tabular}{|c|c|c|c|}
\hline Drug & Concentration $(\boldsymbol{\mu g} / \mathbf{m l})$ & Mean \% assay \pm SD & \% RSD* \\
\hline FF & 10 & $98.12 \pm 1.66$ & 1.54 \\
\hline MF & 20 & $98.67 \pm 1.05$ & 1.39 \\
\hline \multicolumn{4}{|c}{$* n=6$} \\
\hline
\end{tabular}

Table 4: Results of Recovery Studies

\begin{tabular}{|c|c|c|c|c|}
\hline components & Amount added $(\boldsymbol{\mu g} / \mathbf{m l})$ & Amount recovered( $\boldsymbol{\mu g} / \mathbf{m l})$ & \% Recovery \pm SD & \% RSD* \\
\hline \multirow{3}{*}{ FF } & $80 \%(8 \mu \mathrm{g} / \mathrm{ml})$ & 7.82 & $97.75 \% \pm 0.86$ & 1.11 \\
\cline { 2 - 5 } & $100 \%(10 \mu \mathrm{g} / \mathrm{ml})$ & 9.75 & $97.5 \% \pm 0.353$ & 0.87 \\
\cline { 2 - 5 } & $120 \%(12 \mu \mathrm{g} / \mathrm{ml})$ & 11.87 & $98.45 \% \pm 1.20$ & 1.32 \\
\hline \multirow{3}{*}{ MF } & $80 \%(16 \mu \mathrm{g} / \mathrm{ml})$ & 15.62 & $97.6 \% \pm 1.63$ & 1.56 \\
\cline { 2 - 5 } & $100 \%(20 \mu \mathrm{g} / \mathrm{ml})$ & 19.77 & $98.85 \% \pm 0.43$ & 0.95 \\
\cline { 2 - 6 } & $120 \%(24 \mu \mathrm{g} / \mathrm{ml})$ & 23.74 & $98.9 \% \pm 0.31$ & 0.98 \\
\hline
\end{tabular}


Table 5: Summary of Results of Analytical Method Validation

\begin{tabular}{|c|c|c|}
\hline Parameters & FF & MF \\
\hline$\lambda$ max $(\mathrm{nm})$ & $210-220$ & $242-252$ \\
\hline Linearity range $(\mu \mathrm{g} / \mathrm{ml})$ & $3-18$ & $6-21$ \\
\hline Slope & 0.0393 & 0.0102 \\
\hline y-intercept & 0.003 & 0.0017 \\
\hline Correlation Coefficient $\left(\mathrm{R}^{2)}\right.$ & 0.999 & 0.9991 \\
\hline Intraday & 1.36 & 1.27 \\
\hline Inter-day & 1.54 & 1.39 \\
\hline Accuracy $($ Mean $\%$ Recovery $)$ & $97.5-98.45$ & $97.6-98.9$ \\
\hline LOD $(\mu \mathrm{g} / \mathrm{ml})$ & 0.0491 & 0.278 \\
\hline LOQ $(\mu \mathrm{g} / \mathrm{ml})$ & 0.016 & 0.0195 \\
\hline
\end{tabular}

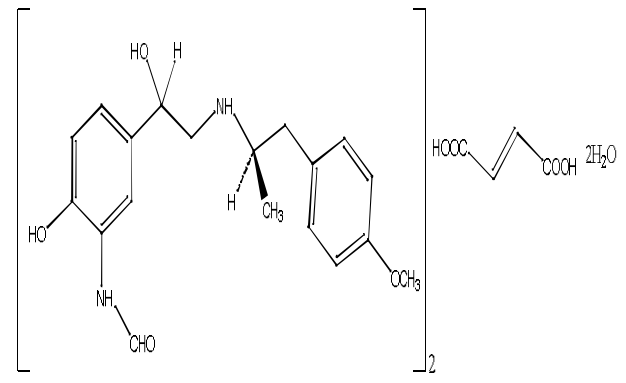

Figure 1: Chemical structure of Formoterol Fumarate dehydrate

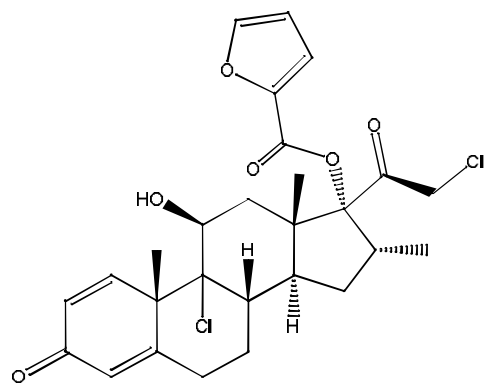

Figure 2: Chemical structure of Mometasone Furoate

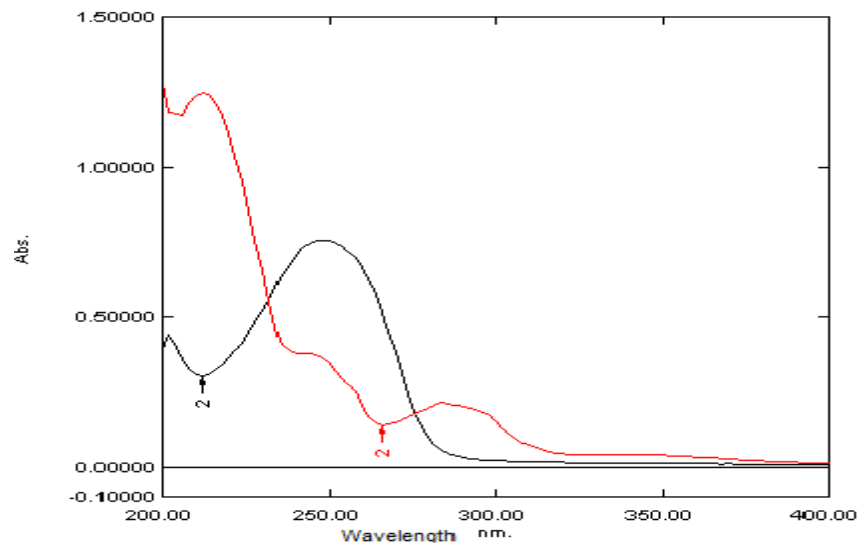

Figure 3: Overlain spectrum of Formoterol Fumarate and Mometasone Furoate in Methanol

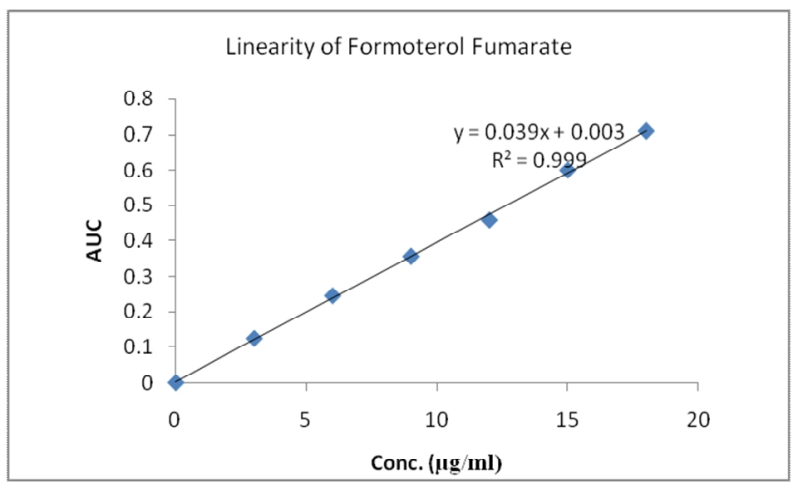

Figure 4: Calibration curve of Formoterol Fumarate at 210-220nm

\section{RESULTS AND DISCUSSION}

The percentage assay of marketed formulation was $98.18 \pm 0.105$ and $98.33 \pm 0.884$, respectively for FF and MF (Table 1), which suggest no interference from the excipients of formulation. The summary of validation parameters for the proposed analytical spectrophotometric method is given in

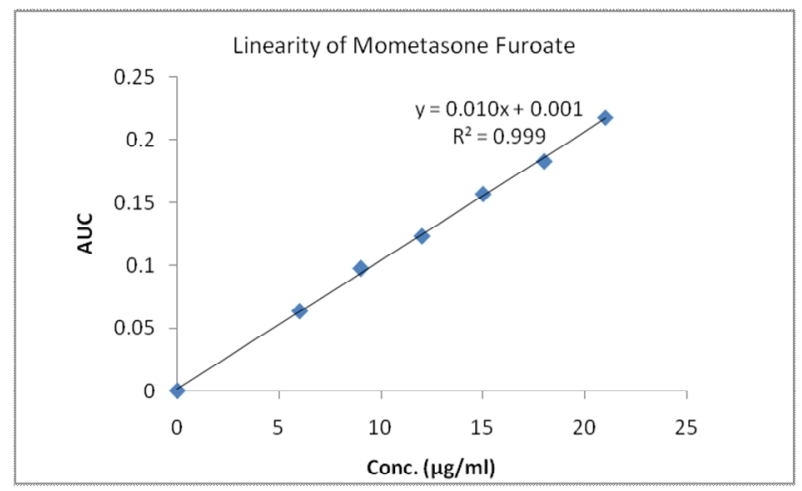

Figure 5: Calibration curve of Mometasone Furoate at 242-252nm

Table 5. Here, correlation coefficients were very close to 1 , suggest that the developed method is following linearity. Results of Table 2 and 3 indicate that the proposed method is precise as \% R.S.D values for intraday as well as inter-day precision were less than $2 \%$. Satisfactory results of $\%$ recovery study (Table 4 ) proved that the developed method is 
accurate. Sensitivity of the method was determined by calculating limit of detection (LOD) and limit of quantification (LOQ). Limit of detection for FF and MF was $0.0491 \mu \mathrm{g} / \mathrm{ml}$ and $0.278 \mu \mathrm{g} / \mathrm{ml}$, respectively. Limit of quantitation with desired accuracy as well precision for FF and MF was found $0.016 \mu \mathrm{g} / \mathrm{ml}$ and $0.0195 \mu \mathrm{g} / \mathrm{ml}$, respectively.

\section{CONCLUSION}

It can be concluded from the results that the proposed spectroscopic method was found to be simple, sensitive, accurate and precise for the analysis of FF and MF in respicaps dosage form. This method was validated as per ICH guidelines. Thus, it can be used for routine quality control studies for assay of FF and MF in bulk and combined dosage form.

\section{ACKNOWLEDGEMENT}

The authors thanks to the Principal, Sinhgad College of Pharmacy, Pune, India for providing the facilities to carry out this work and special thanks to Zydus Cadilla Pvt. Ltd, Ahmadabad, India for providing gift sample of FF and MF API for this research study.

\section{REFERENCES}

1. Neil O, Maryadele J. The Merck Index, An Encyclopaedia of Chemicals, Drugs, and Biologicals, $14^{\text {th }} \mathrm{ed}$, Merck and Co., Inc., Whitehouse Station: New Jersey, USA, Monograph No. 4245; 2006. p. 728

2. Tripathi KD. Essentials of Medical Pharmacology, $6^{\text {th }}$ ed, Jaypee Brothers Medical Publishers (P) Ltd, New Delhi; 2008. p. 213-227

3. Rang HP, Dale MM, Ritter JM, Moore PK. Pharmacology, $5^{\text {th }}$ d, Churchill Livingstone, Elsevier science limited, India; 2003. p. 340-349

4. Dulera official FDA information; Merck and Co., Inc. Whitehouse station, NJ 08889 USA, U.S. Patent No. 6068832; 2013.

5. USP36- NF 31, United States Pharmacopeial Convention, inc. 12601, twarkway, Rockville, official; 2013. p. 3669-70

6. European pharmacopoeia, PHARMEUROPA, EDQM publication, France; $7^{\text {th }}$ ed $2011 ; 2: 2067-2069$.

7. Indian pharmacopoeia, Ministry of Health and Family Welfare, Govt. of India, Published by The Indian Pharmacopoeia Commission Ghaziabad 2007; 2: 527.

8. British pharmacopoeia, Medicines and Healthcare Products regulatory a gency (MHRA), London 2009; 1: 2677, 4033.

9. USP36- NF 31, United States Pharmacopeial Convention, inc. 12601, twarkway, Rockville, official; 2013. p. 4394-95

10. Neil O, Maryadele J. The Merck Index, An Encyclopaedia of Chemicals, Drugs, and Biologicals, $14^{\text {th }} \mathrm{ed}$, Merck and Co., Inc., Whitehouse Station: New Jersey, USA, Monograph No. 6241; 2006. p. 1077
11. European Pharmacopoeia, PHARMEUROPA, EDQM publication, France; $7^{\text {th }}$ ed $2011 ; 2: 2523-2525$.

12. Ahmed S, Jayakar B. Development of reverse phase high performance liquid chromatography method and its validation for estimation of Formoterol Fumarate rota caps, IJPSR 2011; 2 (suppl. 2): 319-324.

13. Akapo S, McCrea C, Gupta J, Chiral. HPLC analysis of Formoterol stereoisomers and thermodynamic study of their interconversion in aqueous pharmaceutical formulations, J Pharm Biomed Anal 2009; 49: 632-637. http://dx.doi.org/10.1016/j.jpba.2008.12.004 PMid:19150186

14. Akapo S, Asif M. Validation of a RP-HPLC method for the assay of formoterol and its related substances in formoterol fumarate dihydrate drug substance, J Pharm Biomed Anal 2003; 33: 935-945. http:// dx.doi.org/10.1016/S0731-7085(03)00425-4

15. Trivedi R, Chendake D, Patel M. A Rapid Stability-Indicating RP-HPLC Method for the Simultaneous Determination of Formoterol Fumarate, Tiotropium Bromide, and Ciclesonide in a Pulmonary Drug Product sci pharm 2012; 80: 591-603.

16. Akapo S, Wegnar M, Mamangun A. Optimization and validation of a gas chromatographic method for analysis of (RS,SR)-diastereoisomeric impurity in formoterol Fumarate, Journal of Chromatography A 2004; 1045:211-216.http://dx.doi.org/10.1016/j.chroma.2004.06.023 PMid: 15378897

17. Gousuddin M, Appala R; Development and validation of Spectrophotometric methods for estimation of Formoterol bulk drug and its pharmaceutical dosage forms, IJPPS 2011; 3( suppl. 3): 306-309.

18. Priyanka G, Santhi priya M. International workshop on transdermal drug delivery system regulatory requirements in asian scenario (homepage on the internet), AP (India), Department of science and technology Government of India; (updated 2012 nov 14, Cited 2013 Feb 8). http://kvsrsiddharthapharma.edu.in/images/booklet.pdf

19. Wang Z, Zhang H, Liu O. Development of an orthogonal method for Mometasone Furoate impurity analysis using supercritical fluid chromatography, Journal of Chromatography A 2011; 1218: 2311-2319. http://dx.doi.org/10.1016/j.chroma.2011.02.027 PMid:21376330

20. Jain HK, Singhai AK, Agrawal RK. Estimation of Losartan Potassium from Tablets. Indian Drugs 2000; 37(5): 239-242.

21. Jain HK, Agrawal RK. Simultaneous Estimation of Gliclazide and Metformin Hydrochloride in Combined Dosage Forms. Indian Journal of Pharmaceutical Sciences 2002; 64: 88-91.

22. Shimadzu Corporation- Kyoto Japan, Analytical and Measuring Instruments Division, Instruction Manual- operation Guide UV-1800; 2008. p. 13.21-13.25.

23. ICH, Q2 (R1) Validation of Analytical Procedures: Text and Methodology, International conf. on Harmonization, Geneva, November; 2005.

\section{Cite this article as:}

Bhangale Pallavi Raghunath, Jain Hemant Kumar. Spectrophotometric method for simultaneous estimation of Formoterol fumarate and Mometasone furoate in respicaps. Int. Res. J. Pharm. 2013; 4(6):220-223 